See discussions, stats, and author profiles for this publication at: https://www.researchgate.net/publication/232940722

\title{
Mimetic theory and scapegoating in the age of cyberbullying: The case of
} Phoebe Prince

Article in Pastoral Care in Education · December 2011

DOI: 10.1080/02643944.2011.626069

CITATIONS

20

2 authors:

89

O'Higgins Norman

Dublin City University

56 PUBLICATIONS 405 CITATIONS

SEE PROFILE
717

J. Connolly

7 PUBLICATIONS 38 CITATIONS

SEE PROFILE

Some of the authors of this publication are also working on these related projects:

Project Minority Faith and Non Religious Post Primary students experiences of a Catholic school ethos View project

Project SonetBull EU Anti-Bullying Project View project 


\section{Mimetic theory and scapegoating in the age of cyberbullying: the case of Phoebe Prince}

\section{James O'Higgins Norman \& Justin Connolly}

To cite this article: James O'Higgins Norman \& Justin Connolly (2011) Mimetic theory and scapegoating in the age of cyberbullying: the case of Phoebe Prince, Pastoral Care in Education, 29:4, 287-300, DOI: 10.1080/02643944.2011.626069

To link to this article: http://dx.doi.org/10.1080/02643944.2011.626069

册 Published online: 22 Nov 2011.

\section{Submit your article to this journal \lceil}

Џ Article views: 527

Q View related articles ๘

4 Citing articles: 4 View citing articles $\sqsubset$ 


\title{
Mimetic theory and scapegoating in the age of cyberbullying: the case of Phoebe Prince
}

\author{
James O'Higgins Norman ${ }^{\mathrm{a} *}$ and Justin Connolly ${ }^{\mathrm{b}}$ \\ ${ }^{a}$ School of Education Studies, Dublin City University, Dublin, Ireland; ${ }^{b}$ All Hallows \\ College, Dublin City University, Dublin, Ireland \\ (Received 7 fuly 2011; final version received 12 August 2011)
}

\begin{abstract}
Whilst traditional forms of bullying have and continue to receive considerable attention in the literature, research on technology-enabled bullying remains in an embryonic stage and considerable deficits exist in our understanding of the nature, extent, dynamics and consequents of this new form of bullying. Of the limited studies that exist on this issue, much relates to the United States. To date, there has been a dearth of comparative data from European countries, including the United Kingdom and Ireland. Furthermore, while questions arise about the way specific technologies might be used as a means of bullying, other questions arise about the extent to which cyberbullying is underpinned by the mimetic process in which scapegoats are identified and victimised within defined populations. This paper will examine the extent to which adolescent cyberbullying is related to social contexts such as post-primary schools and whether it can be explained by Girard's mimetic theory of desire.
\end{abstract}

Keywords: bullying; mimetic theory; cyberbullying

\section{Introduction}

Bullying is a problem that transcends social boundaries and can result in devastating psychological and emotional trauma, including low self-esteem, poor academic performance, depression, and, in some cases, violence and suicide (Parker \& Asher, 1987; Olweus, 1993; Sharp, 1995; Rigby, 1998; Hunt \& Jensen, 2006). In its traditional context, it has been described as being characterised by the following three criteria:

(1) It is aggressive behavior or intentional 'harm doing' (2) which is carried out repeatedly and over time (3) in an interpersonal relationship characterized by an imbalance

\footnotetext{
*Corresponding author. Dublin City University, School of Education Studies, Glasnevin, Dublin 9, Ireland. Email: james.norman@dcu.ie
} 
of power. One might add that the bullying behavior often occurs without apparent provocation,' and 'negative actions can be carried out by physical contact, by words, or in other ways, such as making faces or mean gestures, and intentional exclusion from a group. (Olweus, 1999, pp. 10-11)

While significant research and related strategies have been developed to address bullying among young people in schools, the continued evolution of communications technologies as a means of exchange in society and among young people has presented new challenges where bullying is concerned. The increasing phenomenon of reported experiences of being bullied or harassed through the medium of communications technologies has led to the term cyberbullying being coined by researchers (Willard, 2007a; Hinduja \& Patchin, 2008).

The devastating impact of cyberbullying on adolescents was recently demonstrated in the USA through the death from suicide in January 2010 of a 15-year-old girl called Phoebe Prince. Miss Prince had been subjected to continuous harassment and taunting from some of her classmates at South Hadley High School, much of which was carried out through online social networking sites and through text messages on mobile phones (Boston Globe, 11 May 2010). More recently a similar case occurred in the United Kingdom when 15-year-old Natasha MacBryde killed herself hours after receiving threats on a social networking site (The Guardian, 22 July 2011). If cases like this are to be avoided in the future, educators and legislators alike are going to have to understand the changing nature of bullying as it relates to communications technologies as well as the dynamic of classroom relationships.

Cyberbullying, which is bullying conducted through the medium of electronic communication technologies (such as email, mobile phone, social networking sites, personal digital assistants, instant messaging tools and the World Wide Web), has been defined by Willard as:

\footnotetext{
... being cruel to others by sending or posting harmful material or engaging in other forms of social cruelty using the Internet or other digital technologies, such as cell phones. Young people may be the target of cyberbullying from others or may engage in such harmful behavior. Direct cyberbullying involves repeatedly sending offensive messages. More indirect forms of cyberbullying include disseminating denigrating materials or sensitive personal information or impersonating someone to cause harm. (2007a, p. 10)
}

Willard's attempt to move our understanding beyond the accepted definition of bullying is a recognition that cyberbullying, while connected and in some ways similar, also requires us to revisit our established discourse where bullying is concerned. This paper will outline the latest research on cyberbullying, and examine the context in which this type of victimisation occurs. Finally, we will draw on Girard's mimetic and scapegoating theories to analyse the societal processes at work in cyberbullying.

\section{Cyberbullying}

Researchers highlight that in the physical world adolescents can experience two types of bullying or victimisation, overt and relational (Crick \& Grotpeter, 1995; 
Prinstein et al., 2001; Sullivan, 2006; Dempsey et al., 2009). Overt bullying or victimisation involves physically aggressive behaviours sometimes more associated with males than with females. On the other hand, relational bullying or victimisation involves an intentional manipulation of harm to a victim's social status or relationships and involves behaviours such as social exclusion, rumour-spreading, instigating interpersonal peer conflicts, and divulging personal information (Crick \& Grotpeter, 1995; Dempsey et al., 2009). While modern communications technologies can be used for both overt and relational types of bullying, it is clear that it is within the realm of relational bullying that this medium comes into its own.

A recent study in the United Kingdom found that $22 \%$ of young people have experienced some form of cyberbullying (Smith et al., 2006) while other studies in the USA indicate higher levels of cyberbullying among young people (Hinduja \& Patchin, 2008). A more recent study in Ireland found that one in seven young people in post-primary school had experienced cyberbullying (O'Moore \& Minton, 2011).

As can be seen from the above definitions, there are important distinctions between cyberbullying and traditional or overt bullying. The first set of distinctions relates to the nature of the bullying. Traditional forms of bullying are usually direct and bullies are visible, while cyberbullying can be anonymous and bullies in cyberspace do not have to be physically stronger or bigger than their victims. Secondly, traditional bullying occurs within the scope of time and space, whereas cyberbullying can happen at anytime and anywhere, including in private spaces such as the home. Thirdly, cyberbullying can spread exponentially faster than traditional forms of bullying. For example, a text message or online image can be copied and forwarded to thousands of other people in a matter of minutes. Fourthly, the currency or tools of cyberbullying can be preserved easily (such as saving messages on a phone, memory stick, disk, etc.). Fifthly, traditionally young people who bully usually have poor relationships with adults such teachers; however, it has been found that cyberbullies can have a positive relationship with their teachers (Ybarra \& Mitchell, 2004). Finally, on the one hand, traditional bullying commonly occurs on school property; cyberbullying, on the other hand, frequently occurs outside school property, which makes combating such behaviour much more difficult.

The second set of distinctions between traditional and cyberbullying relates to forms through which cyberbullying is exercised. Cyberbullying forms include: flaming, the sending of angry, rude, vulgar messages about a person to an online group or to that person via email or other text messaging; online harassment, repeatedly sending offensive messages via email or other text messaging to a person; cyberstalking, online harassment that includes threats of harm or is excessively intimidating: denigration or trolling (put-downs), sending harmful, untrue or cruel statements about a person to other people or posting such material online; masquerade, pretending to be someone else and sending or posting material that makes that person look bad; outing, sending or posting material about a person that contains sensitive, private or embarrassing information, including forwarding 
private messages or images; and finally exclusion, cruelly excluding someone from an online group (Trolley et al., 2006; Willard, 2007a). While each of these forms can be said to relate to overt bullying, they are also distinct from it and more specific to the use of technologies as a medium for relational bullying and victimisation.

Finally, the motives as well as the demographic and profile of a cyberbully differ from their offline counterpart (Aftab, 2008). In other words, the anonymity of being online has empowered those who may not have typically shown aggression in an open forum (Shariff, 2008, p. 31). No longer is the bully just the bigger more aggressive child in the school playground. Bullies can now include those one may not usually suspect, being more adept intellectually in their ability to utilise technology as a means of repeated intimidation and harassment. In fact, Goodstein (2007, p. 82) argues that the Internet has 'democratized' bullying, in that it has provided a power to those who would not traditionally had the physical strength to intimidate others.

In a face-to-face situation a bully is usually restricted by the fact that his/her victim can see and even name them and any supporters that might exist. Cyberbullying can provide a layer of protection not traditionally enjoyed by bullies. In the case of school-related bullying, the Internet is open to both classmates and to the world, and it is hard to be completely sure of the identity of person(s) on the other end. The self-doubt and paranoia resulting from being bullied through virtual communications can be debilitating and can manifest in '... poor grades, emotional spirals, poor self-esteem, repeated school absences, depression, and in some cases suicide' (Chait, 2008, p. 7). These outcomes are similar to those arising from traditional bullying; however, with cyberbullying there is often no escape to a safe space. In other words, while the school day is limited by the close of classes, the Internet continues to remain open and accessible to bullies even while the victim is logged off or away from their computer.

\section{Context and problem}

Whilst traditional forms of bullying have and continue to receive considerable attention in the literature, research on technology-enabled bullying remains in an embryonic stage and considerable deficits exist in our understanding of the nature, extent, dynamics and consequents of this new form of bullying. Of the limited studies that exist on this issue, much relates to the United States, with only an emerging comparative data from the United Kingdom, Ireland and other European Union countries (Smith et al., 2006; O’Moore \& Minton, 2011). Consequently, the question as to whether the nature, experiences and impact of cyberbullying among young people in different societies and cultures differ remains an issue requiring further research. This paper aims to redress that imbalance by examining the nature and extent of existing research on adolescent cyberbullying in second-level schools and asking whether our existing understanding of victimhood and violence can be applied to cyberbullying. 
The widespread adoption of information and communications technologies has brought with it many social and educational benefits. Many schools have enthusiastically embraced communications technologies, particularly as it has been found that increasing access to such technology has the potential to increase students' social interaction and enhance collaborative learning experiences (Beran \& $\mathrm{Li}$, 2004). Adolescents have grown up surrounded by ubiquitous technologies that are an embedded part of their daily lives. The use of mobile phones, email, live chat applications and social networking websites is an intrinsic form of their communication and social life (Palfray \& Gasser, 2008). According to a survey in the USA, in 2004 some $45 \%$ of teenagers (aged 12-17) owned a mobile phone. By 2008 that figure had climbed to $71 \%$. Significantly, the study also suggested that $33 \%$ of teenagers send a minimum of 100 texts per day, with $11 \%$ sending more than 200 messages per day. On average, boys send 30 text messages whilst girls send 80 messages on a daily basis. Among teens, age is the most important variable in mobile phone ownership. Older teens are much more likely to own phones than younger teens, and the largest increase occurs at age 14, right at the transition between middle and high school. Among 12-13 year olds, 52\% had a cell phone in 2008. Mobile phone ownership jumped to $72 \%$ at age 14 in that survey, and by the age of 17 more than 8 in 10 teens (84\%) had their own cell phone. The report also states that in $200860 \%$ of teenagers owned a laptop or desktop or, at the very least, had personal access to one in the family home (Lenhart, 2009). While such pervasive adoption of communications technologies confers obvious advantages, particularly with regard to learning and education, these are paralleled by some challenges that to date have not been encountered by many western societies.

One challenge that now presents itself to teachers and other adults is the fact that those who have grown up with communication technologies have a different understanding of privacy than those of previous generations. These 'digital natives' increasingly leave traces of themselves in online public places. Palfrey and Gasser argue that:

at their best, they show off who they aspire to be and put their most creative selves before the world. At their worst, they put information online that may put them in danger, or that could humiliate them in years to come. $(2008$, p. 7$)$

They conclude that young people today are exposing themselves in a way that will benefit marketers, bullies and paedophiles alike, and as such they may end up paying the highest price.

The phenomenon of cyberbullying has grown with the rapid adoption of new technologies such as the Internet and mobile phones. As communication technology has advanced, so too have opportunities for new forms of bullying. Although many teachers and information and communications technology personnel now recognise the problem of school bullying, it is difficult for them to identify when students are being harassed through electronic communication. For example, whereas traditional bullying usually takes the form of physical as well as verbal intimidation, the use of information and communications technologies enable 
harassment and bullying even when the intended target is not physically present. Also, since some 'chat rooms' require passwords it means that, without the victim's' cooperation, it is difficult to identify perpetrator and victim.

Traditional forms of bullying were more easily identifiable and could be dealt with according to individual school policies and government regulations. However, many schools in the United Kingdom, Ireland and the wider European Union have no clear policy on cyberbullying and there seems to be little understanding of how this form of bullying requires a distinct approach. Hence, it is all too easily incorporated into the general school bullying policy with little or no understanding of its uniqueness and impact on students.

Europe has evolved into a culturally and socially diverse society, and yet the factors that predict adolescent cyberbullying remain for the most part a matter of speculation. For example, whether individual factors such as age, gender, ethnicity or religious belief influences cyberbullying remains undetermined. Equally, the influence of situational factors such as attendance at public or private school on cyberbullying outcomes requires investigation. Understanding the influence of these variables would contribute to parents' and educators' understanding of the problem and assist them to recognise and counter it. The increase and impact of cyberbullying requires educators, researchers, administrators and authorities to become proactive and take progressive action. In the first instance this requires a thorough understanding of the problem, its nature and causal factors. However, little research has been conducted in this country to investigate and assist our understanding of this problem.

Whilst empirical research in other countries is also limited, there has at least been earlier recognition of the escalating seriousness of the problem. Ybarra and Mitchell (2004) in the United States reported that $15 \%$ of their sample identified themselves as cyberbullies while $7 \%$ reported being targeted online. In 2004, iSAFE America (a non-profit foundation endorsed by the US Congress and dedicated to the Internet safety education), surveyed 1500 US students in Grades Four to Eight. Data suggested that $42 \%$ were cyberbullied, one in four of these students more than once. In addition, just over one-half $(53 \%)$ of the students in the sample 'cyberbullied' others and one-third of them did so more than once (i-SAFE, 2004).

In Canada, a survey conducted by Mnet (2001) found that one-quarter of young Canadian Internet users in the study sample reported that they had the experience of receiving online messages that made hateful comments about others. Gender differences have also been identified in young adolescents experience related to cyberbullying in Canada ( $\mathrm{Li}, 2006)$.

The limited research on this issue in Europe indicates that the problem of adolescent cyberbullying is equally widespread. For example, a UK report showed that, out of 92 students from 14 different schools, 20 students (or $22 \%$ of the sample), had been victims of cyberbullying at least once, with $6.6 \%$ of the respondents having experienced being cyberbullied frequently (Smith et al., 2006). Finally, a report by O'Moore and Minton (2011) in Ireland found that one in 
seven young people had experienced cyberbullying. Whatever chance parents and teachers had in identifying traditional verbal and physical bullying and intervening, this relatively new form of bullying is far more difficult to identify and is largely dependent on the adolescent talking about it, which is something research has shown young people do not tend to do. Statistics show that $58 \%$ of those who are online bullied do not tell an adult or others about the experience (Juvonen \& Gross, 2008). This unwillingness to tell is not only due to the fact they feel adults may not respond appropriately, but because they fear their Internet usage may be taken by those who are trying to protect them.

According to Beran and $\mathrm{Li}$ (2005), the severity of cyber-harassment also varies with incidents ranging from 'annoying' to 'dangerous' and the occurrence of death threats. In addition, cyberbullying may alter traditional bullying at school. For example, if 'electronic bullies' remain undetected, their bullying behaviours at school may become more severe and direct rather than indirectly exerted against a victim. Clearly, there is a need for research to explore how cyberbullying possibly decreases, maintains or exacerbates other forms of bullying.

Many researchers advocate that it is through education and awareness that progress will be made in the deterrence of cyberbullying (Hinduja \& Patchin, 2008; Kowalski et al., 2008; Shariff, 2008; Willard, 2007b). Common reactive practices by school systems to apply disciplinary and punitive actions against those who engage in cyberbullying have not proven to be particularly effective. Likewise, it is not always clear which school system disciplinary responses against these acts are appropriate in the context of civil law. Reactive measures taken by schools may reduce aggressive incidents from reoccurring by those who are caught, but it takes programmes that instil character and cultivate healthy behaviours to affect longterm changes among young people (Perry, 1999).

The main body of literature on cyberbullying tends to be written from the perspective of the adult, to focus on how adults understand the issue and what they perceive the best practices to be in addressing cyberbullying. There is scant research addressing the viewpoints of adolescents and their experiences of cyberbullying. However, adolescents' voices need to be heard, as their perceptions of the problem have the potential to shed a new light on adult understanding of the issue and would be of particular benefit to parents, teachers, chaplains and educationalists.

\section{Mimetic theory applied to cyberbullying}

While not arguing that one theory explains all forms of harassment, in seeking to understand bullying behaviour among adolescents in schools we turn to the work of René Girard and his mimetic theory. The remainder of this paper will revisit Girard's theory in an attempt to understand cyberbullying as one form of harassment among young people. In order to understand the relationship between Girard's theory and bullying among young people, one must accept that bullying involves violence and victimisation even when it is not expressed overtly and also 
when it occurs through the medium of communication technologies. At the heart of Girard's understanding of violence among people is his argument that rivalry leads us into conflictual behaviour.

For Girard, mimesis relates to a complex process of imitation that occurs among all humans. It is best described as follows:

If the appropriative gesture of an individual named $\mathrm{A}$ is rooted in the imitation of an individual named $\mathrm{B}$, it means that $\mathrm{A}$ and $\mathrm{B}$ must reach together for one and the same object. They become rivals for that object ... [and] violence is the process itself when two or more partners try to prevent one another from appropriating the object they all desire through physical or other means. (Girard, 1996, p. 9)

Girard argued that our desire for objects arises not out of the nature of that which is supposedly desired but out of our desire to imitate each other. He argues that if two individuals desire the same thing, this will soon spread exponentially; and since the initial desire was raised through a desire to imitate another, then the actual object of the desire is forgotten and pure antagonism remains between all those who share the same desire. This antagonism, according to Girard, can only be released through violence and victimisation of an individual who for whatever reason is identified as undermining the shared desire of the group. The purpose of this violence is to release the antagonism among the stronger members of the community without having to attack those whom they wish to imitate as this in a sense would be to attack oneself.

This violence can take the mythical form of a 'ritual sacrifice' of the intended victim that can be viewed as 'a collective action of the entire community, which purifies itself of its own disorder through the unanimous immolation of a victim' (Girard, 1996, p. 11). The result is the 'scapegoat effect' in which:

... two or more people are reconciled at the expense of a third party who appears guilty or responsible for whatever ails, disturbs, or frightens the scapegoaters. They feel relieved of their tensions and they coalesce into a more harmonious group. They now have a single purpose, which is to prevent the scapegoat from harming them, by expelling and destroying him/[her]. (Girard, 1996, p. 12)

Girard (1996) sees victimisation not as an original phenomenon but as a by-product of mimetic rivalry. In his view, 'Violence is mimetic rivalry itself becoming violent as the antagonists who desire the same object keep thwarting each other and desiring the object all the more' (Girard, 1996, pp. 12-13). The victim is perceived by the community of antagonists as being fully responsible for the troubles caused:

The victim cannot be perceived as innocent and impotent; he (or she, as the case may be) must be perceived if not necessarily as a culprit in our sense, at least as a creature truly responsible for all the disorders and ailments of the community, in other words for the mimetic crisis that has triggered the mimetic mechanism of scapegoating ... He is viewed as subversive of the communal order and as a threat to the well-being of the society. His continued presence is therefore undesirable and it must be destroyed or driven away ... by the community itself. (Girard, 1996, p. 15) 
Human beings replace their innate need for aggression and rivalry with each other by scapegoating a victim who is considered to be weak or marginal in the community. For example, young adolescent men who are insecure and who compete with each other for identity, power and masculinity in the school setting will, instead of attacking each other, together attack those who are considered to be weak or easier to destroy such as other young males who do not appear to conform to heteronormativity. Similarly, Cheyne and Pomothy (2000) argue that bullying is also a form of play where children and adolescents practice or rehearse societal norms. For these theorists, the scapegoat is identified to receive aggression because she/he 'is presented as having violated some norm of society or committed some crime that is perceived as a threat to the integrity of the group' (Cheyne \& Pomothy, 2000, p. 4).

Girard argues that in order to justify the scapegoating of an individual the community will be convinced that she/he is a threat to them or that which they desire. Invariably, some form of disability or difference is identified as a focus in the scapegoat by the community, which allows them to justify the violence addressed at the scapegoat. Girard (1996) relies on the example of a boarding school where individuals, who may have difficulty adapting, or who come from another country, or are an orphan, or an only son, or someone who is poor, or even simply the most recent arrival, can be identified as a victim and scapegoated by the community.

The case of Phoebe Prince who in January 2010 died by suicide as a result of being victimised by her high school peers illustrates for us the application of Girard's mimetic theory. In the autumn of 2009, Phoebe moved with her mother and sister from a quiet village on the west coast of Ireland to the Massachusetts town of South Hadley where she enrolled in the ninth grade of her local high school. Phoebe's parents had recently separated and her father remained in Ireland. Evidence from her school work reveals that she deeply missed her father. This may explain why she tended to develop relationships with older boys. However, these relationships were troublesome for her as the two boys to whom she grew closest already had girlfriends and it was not long before Phoebe began to receive negative attention and even distain from other girls at South Hadley High School. While evidence gathered by the local police after Phoebe's death seems to suggest that she received very little by way of overt victimisation, other evidence from the online social network site reveals that Phoebe had become an object of relational victimisation among some of the girls who were close to her male friends at the high school (Bazelon, 2010). In one exchange in January 2010 between two of these girls on Facebook, their scorn for Phoebe is clear: 'Hahaha best night of my life:) ya we kick it with the true Irish not the gross slutter poser ones:)'. Another girl asked if she counted as cute and Irish, and a fourth one chimed in 'like meeee:)'. The first girl answered, 'Yes I love you ... I think you no who im talking about:)'. A couple of girls replied with a chorus of 'hahas'.

The anger towards Phoebe continued in this vain and the number of people involved in victimising her seems to have increased across the school. According to student witnesses who spoke to the police, on one occasion a girl who was not 
directly friends with any of the boys involved but was acquainted with their girlfriends called Phoebe a 'whore' in the cafeteria and 'told her to stay away from "people's men"'. A few minutes later, before the bell rang for class, the same girl walked into a classroom where Phoebe was sitting and publicly rebuked her again. This was not an isolated event according to witnesses. The victimisation of Phoebe also continued through online social network sites including Facebook and Twitter. On 14 January 2010 Phoebe Prince hung herself at home, two days after one girl referred to her on Facebook as an 'Irish slut' (Bazelon, 2010).

There has been much debate in the media about the criminal culpability of the teenagers who victimised Phoebe in the period before she ended her life. The case will ultimately be decided through legal proceedings in the USA. Regardless of the outcome of the related court cases, it is possible for us to see how the behaviour of the bully's at South Hadley towards Phoebe can be said to reflect Girard's mimetic process. Adolescents are deeply concerned about imitating their peers and go to great lengths to ensure that they are accepted by those they wish to emulate. In their desire to imitate they often become rivals and compete with each other for a common object or cause; in this case, for male companions. They are also particularly sensitive to any changes in the status quo where peer relationships are concerned, and will respond aggressively when the subtleties of their world are challenged. Catanzaro (2011) argues that among girls, in particular, motivations for aggression include a myriad of issues such as competition over ideals of beauty and female perfection, jealousies over boys, and a desire for power that is designed to result in respect and popularity.

It is clear that Phoebe Prince's arrival as a newcomer to South Hadley High School and her evolving friendships with two boys in particular challenged the codes already established among girls at the school. By becoming friends with boys who were desired by girls who were already established at the school, Phoebe was placing herself in a position where she would be scapegoated and victimised by those who had an interest in maintaining the existing order among girls at the school. Examined from the perspective of Girard's theory, the girls at South Hadley were already rivals and rather than antagonise each other they scapegoated the new girl. They were able to justify their behaviour by designating her as deviant. In particular, they continually re-enforced her role as deviant from the established order at the school by focusing on her being 'Irish' and by berating her as a 'slut'. By scapegoating Phoebe Prince these girls were saving themselves from having to compete with each other for the affections of the most desired boys at school.

In terms of Girard's mimetic process it is interesting how the antagonism towards Phoebe did not just come from the girls who viewed themselves as having a right to the affections of the boys with whom Phoebe grew close, but also and increasingly from other girls at the high school who victimised Phoebe. Girard explains how, in order to avoid expressing their rivalry with each other, the crowd will focus on a scapegoat who can be sacrificed for the sake of the status quo in the community: 
Those who make up the crowd are always potential persecutors, for they dream of purging the community of the impure elements that corrupt it, the traitors who undermine it. The crowd's act of becoming a crowd is the same as the obscure call to assemble or mobilize, in other words to become a 'mob'. (1996, p.111)

By characterising Phoebe's behaviour as slutty and reinforcing her ethnic identity (i.e. Irish), the mob in this case were identifying Phoebe as a source of impurity who can corrupt the community. Girard explains that once the mob has identified 'an accessible cause that will appease its appetite for violence', they will then go on to victimise her until she is eradicated from the community and the balance of power has been restored.

The new dimension to this process is the use of communications technologies as the medium through which the victim is scapegoated. The arrival of social networking websites such as Facebook and Twitter enable bullies to harass their peers with texts on mobile phones, chat-room conversations and emails. The anonymity provided by these technologies allows a certain level of protection to the bully and removes the need for them to engage in overt victimisation of those who are scapegoated. A recent study by the European Commission's (2010) Safer Internet Programme found that $96 \%$ of 9-16 year olds in the European Union go online on a weekly basis with $60 \%$ using the Internet every day. The highest usage was found in Sweden, Bulgaria, Estonia, Denmark, Norway, the Netherlands, Finland, the Czech Republic, Poland, Slovenia and Lithuania. Regarding social networking, children in the United Kingdom are more likely, at $67 \%$, than their European counterparts $(59 \%)$ to have their own profile, compared with $52 \%$ of children in Ireland. Of importance to teachers and parents alike is the finding that most young people access the Internet either in school or at home, with one-half $(52 \%)$ going online in their bedroom or other private room and more than one-half $(57 \%)$ at a friend's house. Increasingly, young people are using their mobile phones to go online, with $46 \%$ of $9-16$ year olds doing this in Ireland compared with the European Union average of $31 \%$. While most bullying still seems to be overt and to occur off-line, it is clear that the potential for harm and victimisation of young people is significant.

\section{Space here now}

Communications technologies are now firmly embedded in society and most especially among young people. Consequently, the priority for awareness-raising for teachers and parents should be on alerting young people to the nature of the risks they may encounter online whilst encouraging dialogue and greater understanding between parents and children in relation to young people's online activities. As highlighted by Girard, victimisation and scapegoating occurs when an individual can be identified as being different in some way. Too often in our schools those who are perceived as different are targeted and bullied because of their difference. This suggests a lack of appreciate and understanding for diversity. In relation to homophobic and other forms of bullying, research has shown that a 'whole-school' 
approach is key to successful initiatives designed to address bullying (Douglas et al., 2001; Griffin \& Ouellett, 2002; Lee, 2002; Warwick et al., 2004; O'Higgins Norman et al., 2010).

The medium through which the bullying takes place in many ways is incidental but the use of communications technologies does take bullying to a level that is harder for adults to access, where young people are often free from supervision. In order to reduce the risk of bullying generally, and cyberbullying in particular, teachers and parents will have to engage in awareness raising among young people so that they develop an ethical code that will match their use of communications technologies. The case of Phoebe Prince and other similar cases highlight that girls seem to be particularly vulnerable to being scapegoated through cyberbullying, and as such further research and related initiatives on this aspect of bullying will be required.

\section{References}

Aftab, P. (2008) What methods work with the different kinds of cyberbullies? Available online at: http://www.stopcyberbullying.org/educators/howdoyouhandleacyberbully.html (accessed 15 January 2011).

Bazelon, E. (2010, July 20) The untold story of her suicide and the role of the kids who have been criminally charged for it. The Slate. Available online at: http://www.slate.com/id/ 2260952/entry/2260953/ (accessed 5 June 2011).

Beran, T. \& Li, Q. (2004) Is cyber-harassment a significant problem? A report on children's experiences (Calgary, University of Calgary).

Beran, T. \& Li, Q. (2005) Cyber-harassment: a new method for an old behaviour, fournal of Educational Computing Research, 32(3), 265-277.

Catanzaro, M. F. (2011) Indirect aggression, bullying and female teen victimization: a literature review. Pastoral Care in Education, 29(2), 83-101.

Chait, J. (2008) Cyberbullying statistics. Available online at: http://safety.lovetoknow.com/ Cyber_Bullying_Statistics (accessed 9 February 2011).

Cheyne, J. A. \& Pomothy, C. J. (2000) Individual differences in children's perceptions of different forms of bullying, paper presented at the CPA/University of Waterloo Conference on Child Development, Waterloo, Ontario: Canada.

Crick, N. R. \& Grotpeter, J. K. (1995) Relational aggression, gender, and social-psychological adjustment, Child Development, 66(3), 710-722.

Dempsey, A. G., Sulkowski, M., Nichols, R. \& Storch, E. A. (2009) Peer victimization in cyberspace: prevalence and relationship to psychosocial adjustment, Psychology in the Schools, 46, 962-972.

Douglas, N., Kemp, S., Aggleton, P. \& Warwick, I. (2001) The role of external professionals in education about sexual orientation: towards good practice, Sex Education, 1(2), 149-162.

European Commission (2010) Safer Internet programme. Kids online survey. Available online at: http://ec.europa.eu/information_society/apps/projects/factsheet/index.cfm?project_ref=SIP-2008KEP-321803 (accessed 7 November 2011).

Girard, R. (1996) The Girard reader (New York, Crossroad Publishing Company).

Goodstein, A. (2007) Totally wired: what teens and tweens are really doing online (New York, St Martin's Griffin).

Griffin, P. \& Ouellett, M. L. (2002) Going beyond gay straight alliances to make schools safe for lesbian, gay, bisexual and transgender students (Amherst, MA, ILGSS). 
Hinduja, S. \& Patchin, J. W. (2008) Bullying beyond the schoolyard: preventing and responding to cyberbullying (Thousand Oaks, CA, Corwin Press).

Hunt, R. \& Jensen, J. (2006) Education for all: the school report, (London, Stonewall).

i-SAFE (2004) Cyberbullying: statistics and tips. Available online at: http://www.isafe.org/channels/ sub.php?ch=op\&sub_id=media_cyber_bullying (accessed 22 January 2011).

Juvonen, J. \& Gross, E. (2008) Extending the school grounds? Bullying experiences in cyberspace, The fournal of School Health, 78(9), 496-505.

Kowalski, R. M., Limber, S. P. \& Agatston, P. W. (2008) Cyberbullying: bullying in the digital age (Malden, MA, Wiley-Blackwell).

Lee, C. (2002) The impact of belonging to a high school gay/straight alliance, High School fournal, 85(3), 13-26.

Lenhart, A. 2009. National survey on mobile and internet usage, teen data resources. Pew Internet and American Life Project. http://pewinternet.org/topics/Teens.aspx (accessed 7 November 2011).

Li, Q. (2006) Cyberbullying in schools: a research of gender differences, School Psychology International, 27(2), 157-170.

Mnet (2001) Young Canadians in a wired world-Mnet survey. Available online at: http://www. media-awareness.ca/english/special_initiatives/surveys/index.cfm (accessed 18 January 2011).

O’Higgins Norman, J., Goldrick, M. \& Harrison, K. (2010) Addressing homophobic bullying in second-level schools (Dublin, Equality Authority).

Olweus, D. (1993) Bullying at school (Oxford, Blackwell).

Olweus, D. (1999) Sweden, in: P. K. Smith, Y. Morita, J. Junger-Tas, D. Olweus, R. Catalano \& P. Slee (Eds) The nature of school bullying: a cross-cultural perspective (London, Routledge), 7-27.

O’Moore, M. \& Minton, S. (2011) Cyberbullying: the Irish experience. Hauppauge, NY, Nova Publishers.

Palfrey, J. \& Gasser, U. (2008) Born digital: understanding the first generation of digital natives (New York, Basic Books).

Parker, J. G. \& Asher, S. R. (1987) Peer relations and later personal adjustment: are low accepted children at risk? Psychological Bulletin, 102, 357-389.

Perry, C. (1999) Proactive thoughts on creating safe schools, School Community fournal, 9(1), 113-119.

Prinstein, M. J., Boergers, J. \& Vernberg, E. M. (2001) Overt and relational aggression in adolescents: social-psychological functioning of aggressors and victims, Fournal of Clinical Child Psychology, 30, 477-489.

Rigby, K. (1998) Peer relations at school and health of adolescents, Youth Studies, 17(1), 13-17.

Shariff, S. (2008) Cyberbullying: issues and solutions for the school, the classroom and the home (New York, Routledge).

Sharp, S. (1995) How much does bullying hurt? The effects of bullying on the personal well-being and educational progress of secondary aged students. Educational and Child Psychology, 12, 81-88.

Smith, P., Mahdavi, J., Carvalho, M. \& Tippett, N. (2006) UK report: an investigation into cyberbullying, its forms, awareness and impact, and the relationship between age and gender in cyberbullying. Report to the Anti-Bullying Alliance, London. Available online at: http://www.dcsf. gov.uk/research/data/uploadfiles/RBX03-06.pdf (accessed 19 February 2011).

Sullivan, K. W. (2006) Peer victimization in early adolescence: association between physical and relational victimization and drug use, aggression, and delinquent behavior among urban middle school students, Development and Psychopathology, 18(1), 119-137.

Trolley, B., Hanel, C. \& Shields, L. (2006) Demystifying $\mathcal{E}$ deescalating cyberbullying in the schools: a resource guide for counselors, educators and parents. Available online at: http://www. booklocker.com/pdf/2631s.pdf (accessed 16 February 2011). 
Willard, N. (2007a) Cyberbullying and cyberthreats: responding to the challenge of online social aggression, threats, and distress? (Champaign, IL, Research Press).

Willard, N. (2007b) Cybersafe kids, cyber-savoy teens: helping young people learn to use the Internet safely and responsibly? (San Francisco, CA, Jossey-Bass).

Warwick, I., Chase, E., Aggleton, P. \& Sanders, S. (2004) Homophobia, sexual orientation and schools: a review and implications for action (London, Thomas Coram Research Unit, Institute of Education, University of London, and Schools Out).

Ybarra, M. \& Mitchell, K. (2004) Youth engaging in online harassment: associations with caregiver-child relationships, Internet use, and personal characteristics, fournal of Adolescence, 27(3), 319-336. 